\title{
Correction to: Human Systems Engineering and Design
}

Tareq Ahram, Waldemar Karwowski, and Redha Taiar

\section{Correction to: \\ T. Ahram et al. (Eds.): \\ Human Systems Engineering and Design, AISC 876, https://doi.org/10.1007/978-3-030-02053-8}

The original version of the book was inadvertently published with incorrect copyright names in Chapters "Measuring Collaborative Emergent Behavior in Multi-agent Reinforcement Learning", "Products as Mass Media: Entertainment vs. Edification", "Are Teammate Trust and Confidence Dissociable in Risk Intensive Human Machine Teaming?" and "Predicting the Level of Safety Performance Using an Artificial Neural Network", which have now been corrected. The correction chapters and the book have been updated with the changes.

\footnotetext{
The updated versions of the chapters can be found at https://doi.org/10.1007/978-3-030-02053-8_64 https://doi.org/10.1007/978-3-030-02053-8_65

https://doi.org/10.1007/978-3-030-02053-8_106 https://doi.org/10.1007/978-3-030-02053-8_107 